\title{
Idarucizumab, a humanized monoclonal antibody fragment, for reversal of Dabigatran therapy for atrial fibrillation
}

\author{
Osmar Antonio Centurión ${ }^{1 *}$, Nelson Javier Aquino ${ }^{2}$, Laura Beatriz García ${ }^{2}$ and Judith María Torales ${ }^{2}$ \\ ${ }^{1}$ Department of Health Sciences's Investigation, Sanatorio Metropolitano, Fernando de la Mora, Paraguay \\ ${ }^{2}$ Cardiology Department, Clinic Hospital, Asuncion National University, Paraguay
}

The prevalence of atrial fibrillation (AF) increases with age, and the elderly are the fastest growing subset of the population. It has been estimated that there will be 12 million patients with AF in the United States within the next several decades [1-5]. Actually, AF is the most common sustained arrhythmia encountered in the field of internal medicine. AF has a prevalence of approximately $1 \%$ and a lifetime risk of approximately $25 \%$ after the age of $40[1,2]$. The annual risk of stroke ranges from $2 \%-18 \%$ depending on other risk factors [3]. Atrial fibrillation shares strong epidemiological associations with other cardiovascular diseases such as heart failure and coronary artery disease [6-10]. Many fundamental aspects of AF have been poorly understood until quite recently, and there are several features on the mechanisms of AF that makes it difficult to manage it properly [10-12]. AF may present in a wide variety of clinical conditions. The optimal management strategy for an individual patient with AF depends on the patient's underlying condition.

AF increases the overall risk of stroke five-fold, and is associated with particularly severe strokes. About $76 \%$ of AF patients have a moderate to high risk of embolic complications, and they have also a significant risk factor for stroke recurrence [13-15]. Therefore, AF carries a high risk for thromboembolic events and any patient with at least two moderate risk factors, and probably even one, should be on oral anticoagulation. Balancing the risk of bleeding and thromboembolism is crucial in the management of patients with AF. Antithrombotic therapy reduces the risk of stroke in patients with $\mathrm{AF}$, and Warfarin has been shown to have a relative risk reduction of approximately $60 \%$ compared with control and to be significantly more effective than Aspirin [16,17]. Therefore, for over five decades, oral anticoagulation with Warfarin has become the standard of care for stroke prevention in patients with AF [18]. Warfarin, however, has limitations, including multiple interactions with other drugs and foods, genetic variability in metabolism, delayed onset and offset, and the need for frequent monitoring and dose adjustments. Given the limitations of Warfarin, clinicians and clinical investigators have been interested in the development of newer oral anticoagulants [19-21]. Therefore, there have been studies investigating the efficacy and safety of these agents. The Randomized Evaluation of Long-Term Anticoagulation Therapy (RE-LY) was a large, multicenter, randomized trial designed to compare two fixed doses of Dabigatran $(110 \mathrm{mg}$ and $150 \mathrm{mg}$ ), each administered in a blinded manner, with open-label use of Warfarin in AF patients who were at increased risk for stroke [19]. The primary study outcome was stroke or systemic embolism. The primary safety outcome was major hemorrhage. Secondary outcomes were stroke, systemic embolism, and death. Other outcomes were myocardial infarction, pulmonary embolism, transient ischemic attack, and hospitalization. The primary net clinical benefit outcome was the composite of stroke, systemic embolism, pulmonary embolism, myocardial infarction, death, or major hemorrhage. The rate of the primary outcome was significantly lower with Dabigatran at a dose of $150 \mathrm{mg}$ twice daily (1.11\% per year) than with either Dabigatran at a dose of $110 \mathrm{mg}$ twice daily (1.53\% per year) or Warfarin (1.69\% per year). Both doses of Dabigatran were noninferior to warfarin $(\mathrm{p}<0.001)$, and the higher dose of Dabigatran was even superior to Warfarin $(\mathrm{p}<0.001)$. The rate of non-hemorrhagic stroke was also significantly lower with $150 \mathrm{mg}$ of Dabigatran (0.92\% per year) than with either $110 \mathrm{mg}$ of Dabigatran (1.34\% per year) or Warfarin (1.20\% per year). The rates per year of hemorrhagic stroke with the 110 -mg and 150 mg Dabigatran doses $(0.12 \%$ and $0.10 \%)$ were significantly lower than that with Warfarin $(0.38 \%)$. The rate of extracranial hemorrhage was similar in all three groups: $2.51 \%$ with $110 \mathrm{mg}$ of Dabigatran, $2.84 \%$ with $150 \mathrm{mg}$ of Dabigatran, and $2.67 \%$ with Warfarin. In summary, the RE-LY trial showed that compared with Warfarin the oral direct thrombin inhibitor, Dabigatran etexilate given at a dose of $150 \mathrm{mg}$ twice daily reduces stroke with less intracranial bleeding, and Dabigatran 110 $\mathrm{mg}$ twice daily has similar efficacy with less bleeding [19]. The rate of major bleeding was $3.36 \%$ per year in the Warfarin group, as compared with $2.71 \%$ per year in the group that received $110 \mathrm{mg}$ of Dabigatran (relative risk with Dabigatran, $0.80 ; 95 \% \mathrm{CI}, 0.69$ to $0.93 ; \mathrm{P}=0.003$ ) and $3.11 \%$ per year in the group that received $150 \mathrm{mg}$ of Dabigatran [19].

Despite this better performance of dabigatran than warfarin in the bleeding scenario, there are still various emergent situations where the presence of Dabigatran in the blood system may worsen the hemorrhagic event [22-24]. Serious bleeding can occur. For example, a life-threatening bleeding complication can occur. Moreover, dabigatran-treated patients may sustain trauma, and may require urgent surgery or intervention. Additionally, dabigatran can increase the risk of perioperative bleeding. In order to improve the medical management of such patients, a specific dabigatran-reversal agent was synthesized. Idarucizumab, a humanized monoclonal antibody

Correspondence to: Prof. Dr. Osmar CA, Professor of Medicine, Faculty of Medical Sciences,Asunción National University, Department of Health Sciences's Investigation, Sanatorio Metropolitano. Teniente Ettiene $215 \mathrm{c} /$ Ruta Mariscal Estigarribia, Fernando de la Mora, Paraguay, Tel: 595-21-421423 E-mail: osmarcenturion@hotmail.com

Key words: idarucizumab. dabigatran. atrial fibrillation

Received: April 25, 2017; Accepted: May 25, 2017; Published: May 29, 2017 
fragment, binds dabigatran with an affinity that is 350 times as high as that observed with thrombin [25-27]. Consequently, idarucizumab binds free and thrombin-bound dabigatran and neutralizes its activity. In healthy young volunteers with normal renal function, as well as, in elderly volunteers with mild or moderate renal impairment, the administration of idarucizumab produced immediate and complete reversal of the anticoagulant effects of dabigatran without procoagulant effects [28-30].

There are interesting studies on Idarucizumab at present time that we can't discuss them all in this editorial. One the most important studies is The RE-VERSE AD study which was undertaken to examine the efficacy and safety of idarucizumab in dabigatran-treated patients who had serious bleeding or required urgent procedures [31]. Idarucizumab rapidly and completely reversed the anticoagulant effect of dabigatran in 88 to $98 \%$ of the patients who had had elevated clotting times at baseline. Idarucizumab obviated the need for intervention in 1 of the 3 patients in group B who did not undergo a procedure. Among the 36 patients who underwent a procedure, normal hemostasis was reported in $92 \%$ and mild-to-moderate impairment in the remaining $8 \%$. The 5-g dose of idarucizumab that was used in this study to reverse the effects of dabigatran was chosen on the basis of the highest range of plasma concentrations measured in the RE-LY trial. Immediately after the administration of idarucizumab, the concentration of unbound dabigatran was reduced to a level at or near the lower limit of quantification in all but 1 patient, resulting in normalization of the dilute thrombin time and the ecarin clotting time. There were no safety concerns among the 90 patients involved in this study. Evidently, the efficient development of idarucizumab to rapidly and completely reverse the anticoagulant activity of dabigatran is an important therapeutic advance with clinical implication. Therefore, idarucizumab is likely to be the treatment of choice for patients who present with dabigatran-induced uncontrolled or life-threatening bleeding or for those AF patients on dabigatran who require urgent surgery or invasive procedures.

\section{References}

1. Heeringa J, van der Kuip DA, Hofman A, Kors JA, van Herpen G (2006) Prevalence, incidence and lifetime risk of atrial fibrillation: the Rotterdam study. Eur Heart $J$ 27: 949-953. [Crossref]

2. Go AS, Hylek EM, Phillips KA, Chang Y, Henault LE, et al. (2001) Prevalence of diagnosed atrial fibrillation in adults: national implications for rhythm management and stroke prevention:the AnTicoagulation and Risk Factors in Atrial Fibrillation (ATRIA) Study. JAMA 285: 2370-2375. [Crossref]

3. Feinberg WM, Blackshear JL, Laupacis A, Kronmal R, Hart RG (1995) Prevalence, age distribution, and gender of patients with atrial fibrillation. Analysis and implications. Arch Intern Med 155: 469-473. [Crossref]

4. Singer DE, Albers GW, Dalen JE, Go AS, Halperin JL, et al. (2004) Antithrombotic therapy in atrial fibrillation: theSeventh ACCP Conference on Antithrombotic and Thrombolytic Therapy. Chest 126: 429S-456S. [Crossref]

5. Miyasaka Y, Barnes ME, Gersh BJ, Cha SS, Bailey KR, et al. (2006) Secular trends in incidence of atrial fibrillation in Olmsted County, Minnesota: 1980 to 2000, and implications on the projections for future prevalence. Circulation 114: 119-125. [Crossref]

6. Centurión OA, Shimizu A, Isomoto S, Konoe A, Kaibara M, et al. (2005) Influence of advancing age on fractionated right atrial endocardial electrograms. Am J Cardiol 96: $239-242$.

7. Shimizu A, Centurion OA (2002) Electrophysiological properties of the human atrium in atrial fibrillation. Cardiovasc Res 54: 302-314. [Crossref]

8. Centurión OA, Shimizu A, Isomoto S, Konoe A (2008) Mechanisms for the genesis of paroxysmal atrial fibrillation in the Wolff-Parkinson-White syndrome: Intrinsic atrial muscle vulnerability vs. electrophysiological properties of the accessory pathway. Europace 10: 294-302. [Crossref]

9. Hashiba K, Centurión OA, Shimizu A (1996) Electrophysiologic Properties of the human atrial muscle in paroxysmal atrial fibrillation. Am Heart $J$ 131: 778-789.

10. DiMarco JP (2009) Atrial fibrillation and acute decompensated heart failure. Circ Heart Fail 2: 72-73. [Crossref]
11. Miyasaka Y, Barnes ME, Bailey KR, Cha SS, Gersh BJ, et al. (2007) Mortality trends in patients diagnosed with first atrial fibrillation: a 21 -year community based study. $J$ Am Coll Cardiol 49: 986-992. [Crossref]

12. Miyasaka Y, Barnes ME, Gersh BJ, Cha SS, Bailey KR, et al. (2008) Changing trends of hospital utilization in patients after their first episode of atrial fibrillation. $\mathrm{Am} \mathrm{J}$ Cardiol 102: 568-572. [Crossref]

13. Nieuwlaat R, Capucci A, Camm AJ, Olsson SB, Andresen D et al. (2005) Atrial fibrillation management: a prospective survey in ESC member countries:the Euro Heart Survey on Atrial Fibrillation. Eur Heart J 26: 2422-2434. [Crossref]

14. Lip GY, Huber K, Andreotti F, Arnesen H, Airaksinen KJ, et al. (2010) Management of antithrombotic therapy in atrial fibrillation patients presenting with acute coronary syndrome and/or undergoing percutaneous coronary intervention/ stenting. Thromb Haemost 103: 13-28. [Crossref]

15. Gage BF, Waterman AD, Shannon W, Boechler M, Rich MW, et al. (2001) Validation of clinical classification schemes for predicting stroke: results from the National Registry of Atrial Fibrillation. JAMA 285: 2863-2870. [Crossref]

16. McNamara RL, Tamariz LJ, Segal JB, Bass EB (2003) Management of atrial fibrillation: review of the evidence for the role of pharmacologic therapy, electrical cardioversion, and echocardiography. Ann Intern Med 139: 1018-1033. [Crossref]

17. Hart RG, Pearce LA, Aguilar MI (2007) Meta-analysis: antithrombotic therapy to prevent stroke in patients who have nonvalvular atrial fibrillation. Ann Intern Med 146: 857-867. [Crossref]

18. Connolly S, Pogue J, Hart R, Pfeffer M, Hohnloser S, et al. (2006) Clopidogrel plus aspirin versus oral anticoagulation for atrial fibrillation in the Atrial Fibrillation Clopidogrel Trial with Irbesartan for prevention of Vascular Events (ACTIVE W): a randomised controlled trial. Lancet 367: 1903-1912.

19. Connolly SJ, Ezekowitz MD, Yusuf S, Eikelboom J, Oldgren J, et al. (2009) Dabigatran versus warfarin in patients with atrial fibrillation. $N$ Engl J Med 361: 1139-1151. [Crossref]

20. Centurión OA (2010) Dabigatran, a direct thrombin inhibitor in trial fibrillation: ¿Is it already time for a change in oral anticoagulation therapy? J Atrial Fib 1: 601-605.

21. Centurión OA (2014) Efficacy and safety of Dabigatran etexilate utilization with concomitant dual antiplatelet therapy in atrial fibrillation. $J$ Atrial Fib 6: 54-58.

22. Yeh CH, Gross PL, Weitz JI (2014) Evolving use of new oral anticoagulants for treatment of venous thromboembolism. Blood 124: 1020-1028. [Crossref]

23. Graham DJ, Reichman ME, Wernecke M, et al. (2015) Cardiovascular, bleeding, and mortality risks in elderly Medicare patients treated with dabigatran or warfarin for nonvalvular atrial fibrillation. Circulation 131: 157-164. [Crossref]

24. Van Ryn J, Stangier J, Haertter S, et al (2010) Dabigatran etexilate-a novel, reversible, oral direct thrombin inhibitor: interpretation of coagulation assays and reversal of anticoagulant activity. Thromb Haemost 103: 1116-1127. [Crossref]

25. Schiele F, van Ryn J, Canada K, et al. (2013) A specific antidote for dabigatran functional and structural characterization. Blood 121: 3554-3562. [Crossref]

26. Glund S, Moschetti V, Norris S, et al. (2015) A randomised study in healthy volunteers to investigate the safety, tolerability and pharmacokinetics of idarucizumab, a specific antidote to dabigatran. Thromb Haemost 113: 9439-9451. [Crossref]

27. Glund S, Stangier J, Schmohl M, et al. (2015) Safety, tolerability, and efficacy of idarucizumab for the reversal of the anticoagulant effect of dabigatran in healthy male volunteers: a randomised, placebo-controlled, double-blind phase 1 trial. Lancet 386: 680-690

28. Norris S, Ramael S, Ikushima I, Haazen W, Harada A, et al. (2017) Evaluation of the immunogenicity of the dabigatran reversal agent idarucizumab during Phase I studies. Br J Clin Pharmacol.

29. Schmohl M, Glund S, Harada A, Imazu S, De Smet M, et al. (2017) Idarucizumab does not have procoagulant effects: Assessment of thrombosis biomarkers in healthy volunteers. Thromb Haemost. 117: 269-276.

30. Glund S, Stangier J, van Ryn J, Schmohl M, Moschetti V, et al. (2017) Effect of Age and Renal Function on Idarucizumab Pharmacokinetics and Idarucizumab-Mediated Reversal of Dabigatran Anticoagulant Activity in a Randomized, Double-Blind, Crossover Phase Ib Study. Clin Pharmacokinet. 56: 41-54.

31. Pollack CV Jr, Reilly PA, Eikelboom J, Glund S, Verhamme P, et al. (2015) Idarucizumab for Dabigatran Reversal. $N$ Engl J Med 373: 511-520. [Crossref]

Copyright: (C2017 Centurión OA. This is an open-access article distributed under the terms of the Creative Commons Attribution License, which permits unrestricted use, distribution, and reproduction in any medium, provided the original author and source are credited. 